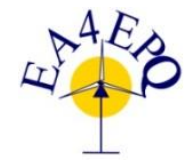

19th International Conference on Renewable Energies and Power Quality (ICREPQ'21)

\title{
The Fault Detection of Gears of Electromechanical Power Transmission System using Frequency Domain Approach
}

\author{
Alwadie. A ${ }^{1}$, Muhammad Irfan ${ }^{2}$, , Nordin Saad ${ }^{3}$ \\ ${ }^{1,2}$ Electrical Engineering Department, College of Engineering, Najran University \\ King Abdulaziz Road, Najran, Saudi Arabia \\ ${ }^{3}$ Department of Electrical and Electronics Engineering, Universiti Teknologi PETRONAS, 31750 Bandar Seri \\ Iskandar, Perak, Malaysia \\ alwadie@hotmail.com ${ }^{1}$, miditta@nu.edu.sa ${ }^{2}$, nordiss@utp.edu.my ${ }^{3}$
}

\begin{abstract}
Electric motors are widely used in the industry and convert electrical power to mechanical power. Gears are connected with the motor shaft for frictionless power transmission. The power transmission efficiency is dropped when the gear teeth is damaged. It causes huge financial loss. There are various commercially available condition monitoring tools for the preventive maintenance and condition monitoring of the gearing systems. However, such tools and techniques are intrusive and costly. This paper presents a non-intrusive approach for timely detection of gear damages and can be integrated to existing condition monitoring systems to save time and cost. The proposed method is based on the analysis of power spectra of the frequency amplitude plots. The amplitude difference at gear harmonics gives indication of the presence of the fault. The proposed technique has been tested and validated at $1400 \mathrm{rpm}$ and $1370 \mathrm{rpm}$ of the motor which is operating at $75 \%$ load and full load.
\end{abstract}

Keywords: Instantaneous Power Analyzer; Gear Anomaly; Gear Cracks, Machine Reliability, Condition Monitoring.

\section{Introduction}

The toothed wheels are known as gears. The two gears are meshed to transfer the mechanical power. The gear connected with the prime mover is call primary gear and the gear to which the power is being transmitted is called follower gear [1-3]. Gears are modified version of the friction wheel to eradicate the slipping. The gears are used in the machinery where the definite velocity ratio is required. There are various types of gears such as helical gears, spur gears, hypoid gear, bevel gear, worm gear, spiral gear, ground gear and angular gear $[4,5]$. The gears are the important element of the machines and failure of the gear results in the failure of the machine. The machine failures cause disturbances on the production lines and eventually creates financial losses in the form of production loss and maintenance cost. Thus, the reliable of operation of the gears gains importance and various strategies are adopted in the industry to protect the gears from faults and to predict the failures through various condition monitoring strategies to avoid the emergency shutdowns of the production lines [6-9].

The literature review indicates a lot of techniques associated with the condition monitoring of gear transmission system. For example, acoustic emission was used in [10] to detect the gear shaft misalignment. Similarly, oil film thickness was used as indicator of gear health [11]. The wavelet transform along with artificial intelligence approach was utilized by [12] to detect the faults in helical gearing system. A vibration analysis approach based on time-frequency analysis was proposed in $[13,14]$ for the condition monitoring of gears. A combination of support vector machine and genetic algorithms was proposed in [15] to analyze the faults in gear transmission system. The infrared thermography-based method was proposed by [16] to diagnose the faults in gears. The time domain features were extracted from infrared images and were classified using artificial intelligence algorithm. Although the methods described in [10-16] shows promising results in detecting the gear transmission faults, however, these methods are intrusive, costly and complex. A non-intrusive approach utilize machine current signatures was used by $[17,18]$ for investigation of gear faults. However, the method offers only two fault components and their amplitudes were affected by noise and challenge the reliability of the condition monitoring system.

The contribution of this paper is to present a non-intrusive gear transmission condition monitoring system based on analysis of amplitudes on gear frequencies analyzed in power spectrum.

The rest of the paper has been organized as follows: the hardware and software interface for experiments has been illustrated in section 2 . The results are described in section 3 and conclusion has been given in section 4 . 


\section{Hardware and Software Interface}

The hardware used in the test rig development consists of a speed sensor, a current sensor, a voltage sensor, a frequency drive, an induction motor, gear box, steel frame. The software used in the project was LabVIEW. The components of the test rig and their interface scheme has been shown in Figure 1. The flow chart of the gear condition monitoring system has been shown in Figure 2. The LabVIEW front panel and block diagram are shown in Figure 3. The frequency harmonics of the gear as shown in Table I are calculated using the mathematical formula reported in the literature $[2,3,7,9]$.

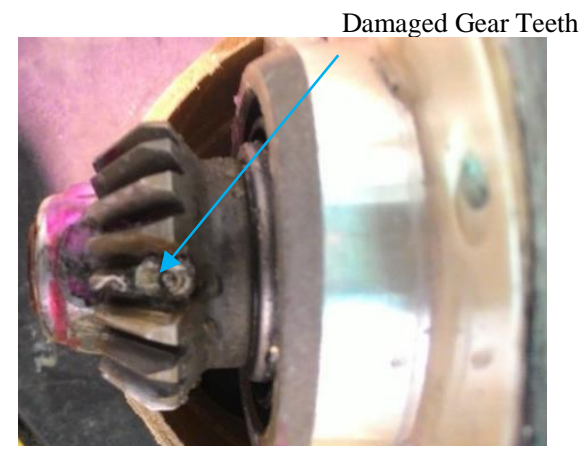

Induction motor

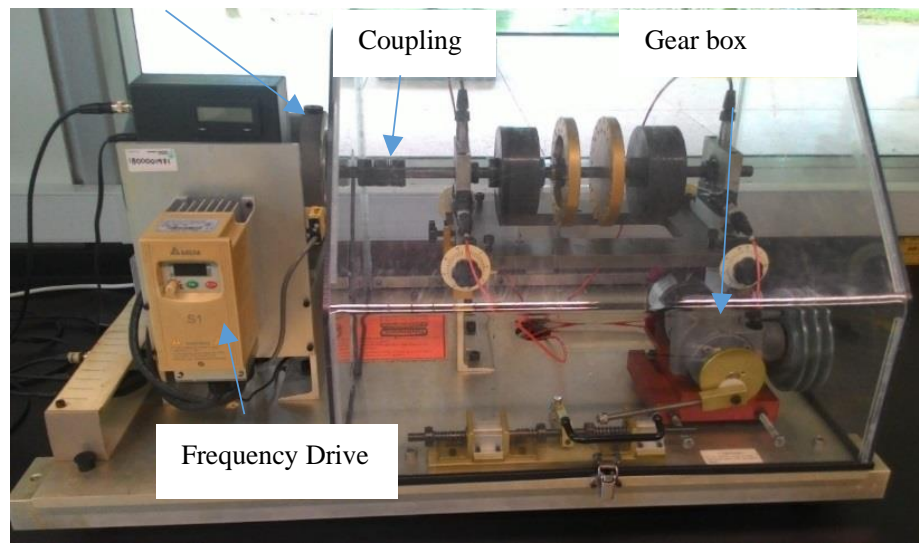

(d)

Fig. 1. The components of the test rig (a) damaged gear (b) complete setup

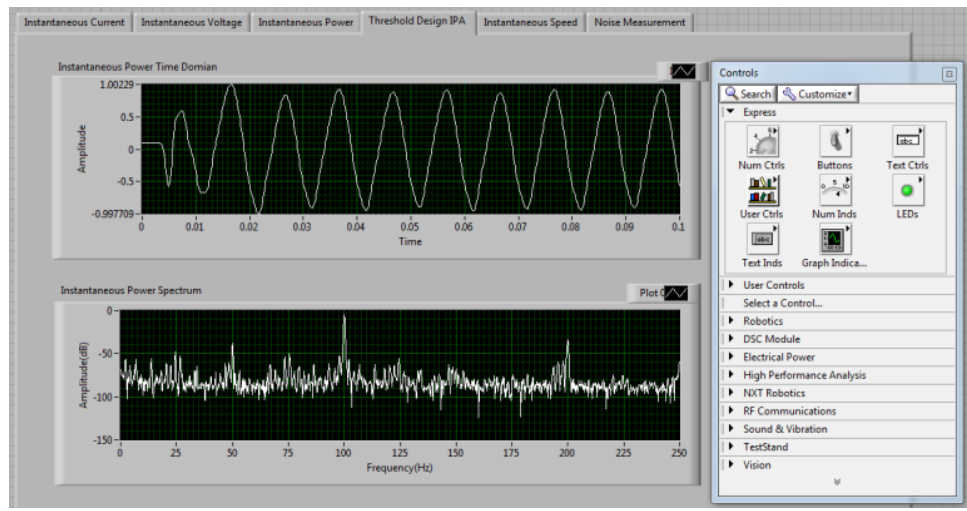

(a) 


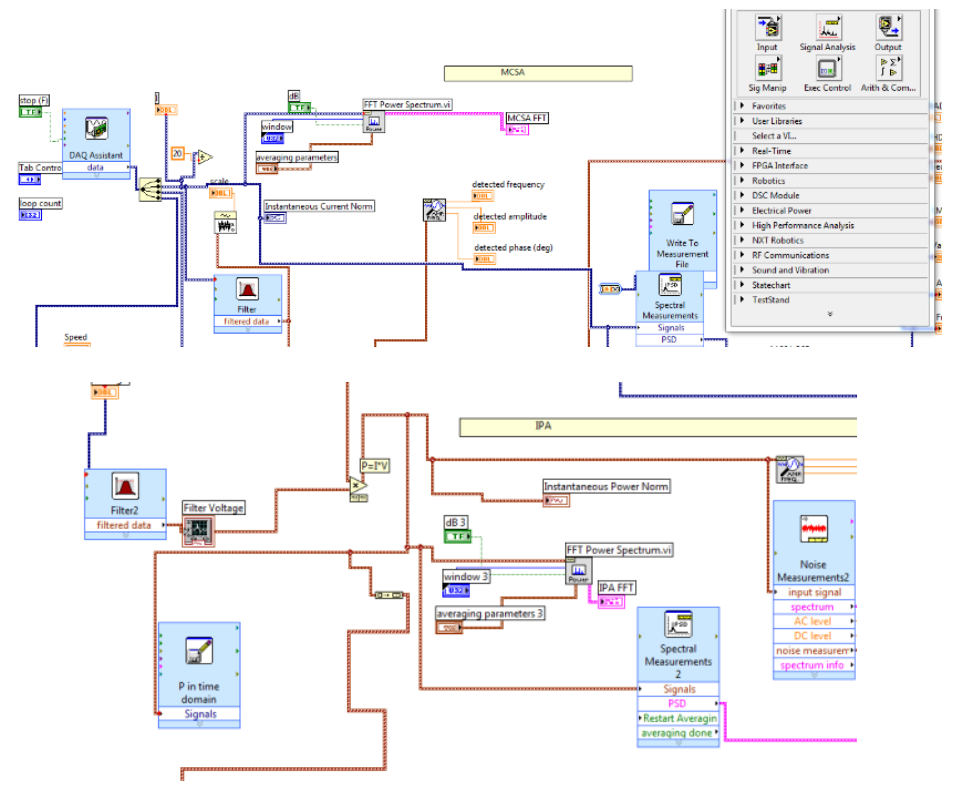

(b)

Fig. 2. The LabVIEW window (a) HMI window (b) LabVIEW code

Table I. Gear frequencies for fault localization in Amplitude-Frequency Plot

\begin{tabular}{|c|c|c|c|}
\hline \multirow{2}{*}{ Speed (rpm) } & \multicolumn{3}{|c|}{ Gear Fault Harmonics } \\
\cline { 2 - 4 } & $f_{g}(\mathrm{~Hz})$ & $\begin{array}{c}\text { Left Harmonics } \\
(\mathrm{Hz})\end{array}$ & $\begin{array}{c}\text { Right } \\
\text { Harmonics }(\mathrm{Hz})\end{array}$ \\
\hline 1400 & 23.4 & 76.6 & 123.4 \\
\hline 1370 & 22.8 & 77.20 & 122.8 \\
\hline
\end{tabular}

\section{Results and Discussions}

The frequency vs amplitude plots of the machine power spectra has been shown in Figure 3 and 4 for two operating conditions of $1400 \mathrm{rpm}$ and $1370 \mathrm{rpm}$. The values of the amplitudes for the normal gear in Figure 3 (a) are $-87.49 \mathrm{db},-66.82 \mathrm{db}$ and -60.43 $\mathrm{db}$ at three harmonic components $23.4 \mathrm{~Hz}, 76.6 \mathrm{~Hz}, 123.4 \mathrm{~Hz}$. While, Figure 3(b) shows amplitudes values $-65.31 \mathrm{db},-44.48$ $\mathrm{db},-38.28 \mathrm{db}$ at three harmonic components $23.4 \mathrm{~Hz}, 76.6 \mathrm{~Hz}$, 123.4 Hz. Figure 3 shows that the $22 \mathrm{db}$ difference in amplitude values appears when a damaged gear is connected with the motor. This $22 \mathrm{db}$ difference in amplitudes serves as the indicator of damaged gear in automated gear condition monitoring system when machine is operating at $1400 \mathrm{rpm}$. Similarly, Figure 4 (a) and (b) represents the frequency vs amplitude plots for the normal gear and damages gear @ 1370 rpm. A amplitude difference of $28 \mathrm{db}$ has been recorded by comparing the spectra of Figure 4 (a) and (b). This $28 \mathrm{db}$ difference in amplitudes serves as the indicator of damaged gear in automated gear condition monitoring system when machine is operating at $1370 \mathrm{rpm}$. The summary of amplitude variations has been depicted in Table II.

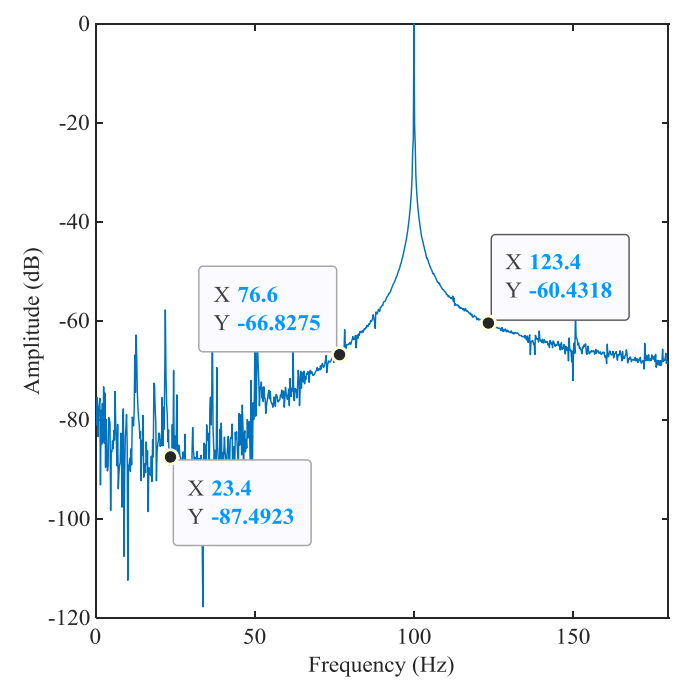

(a) 


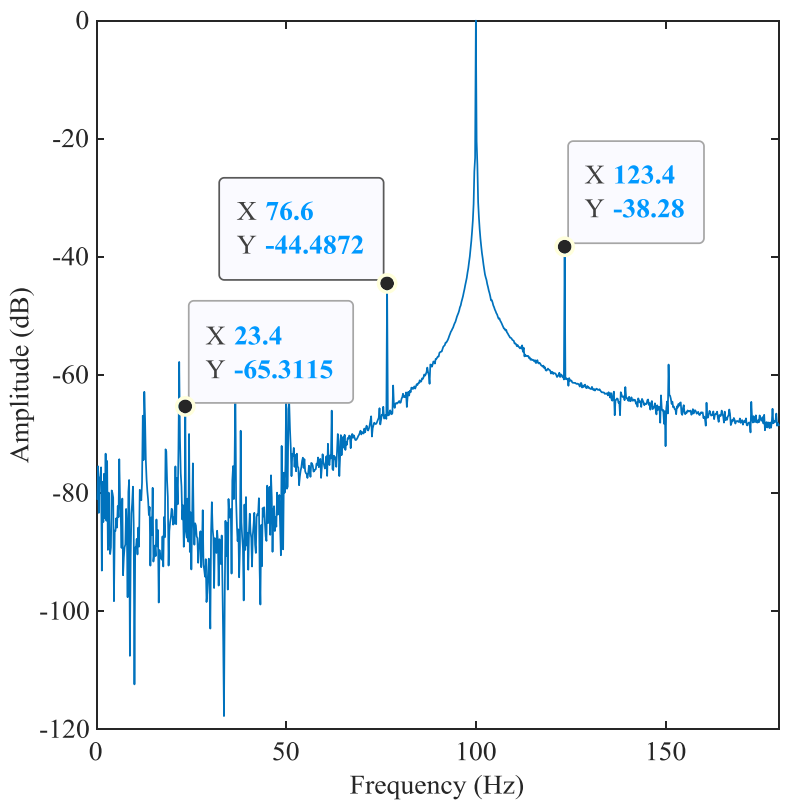

(b)

Fig. 3.The instantaneous power spectra of the (a) healthy gear (b) faulty gear

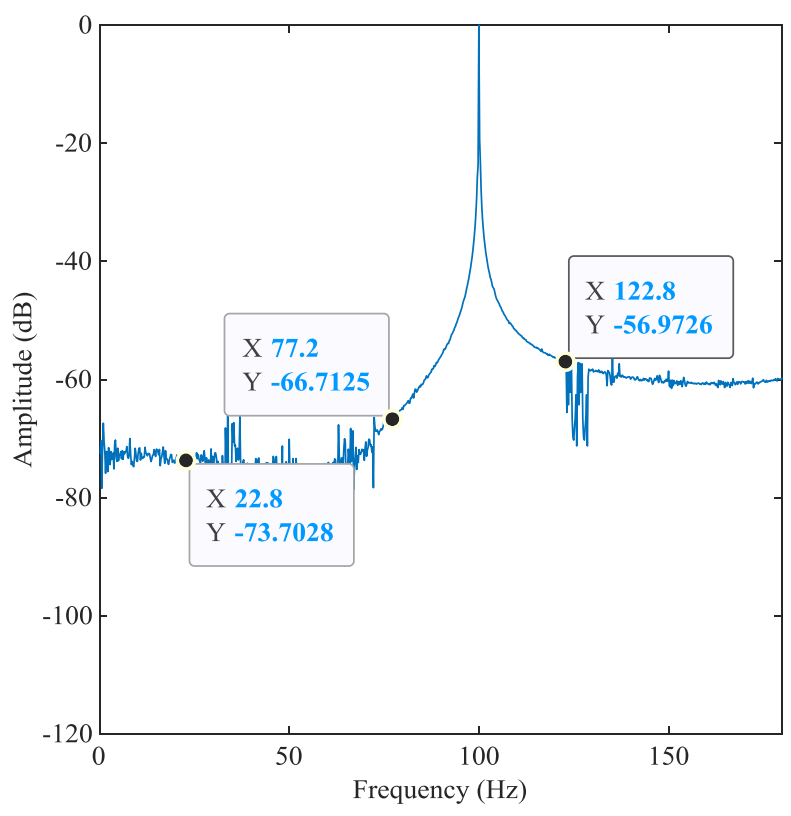

(a)

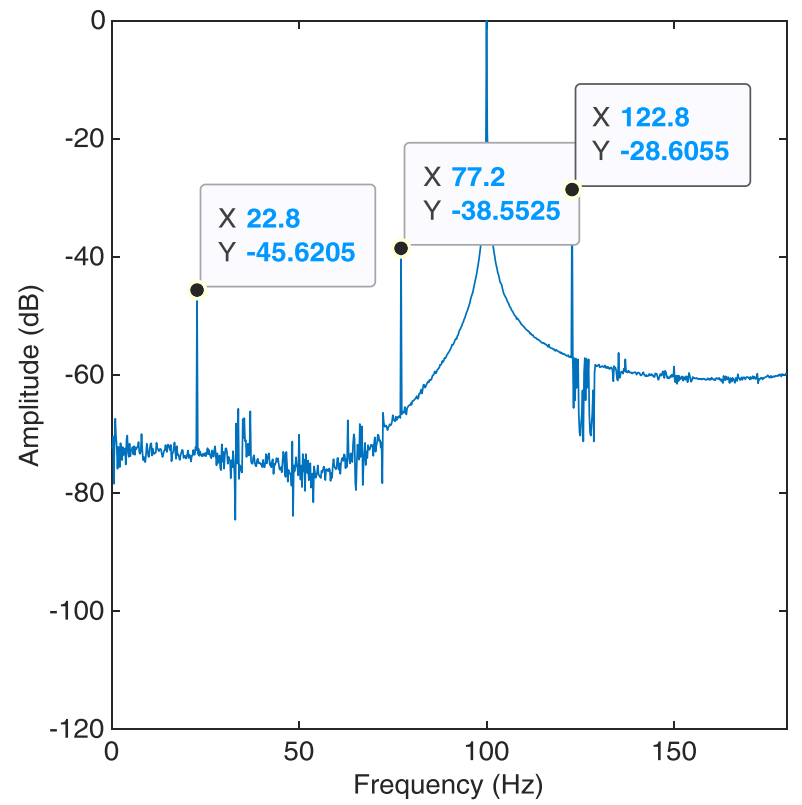

(b)

Fig. 4.The instantaneous power spectra of the (a) healthy gear (b) faulty gear

Table II. Amplitude Variations Summary

\begin{tabular}{|c|c|c|c|}
\hline $\begin{array}{c}\text { Machine Shaft } \\
\text { RPM }\end{array}$ & $\begin{array}{c}\text { Non-Fault } \\
\text { Condition } \\
\text { Amplitudes }\end{array}$ & $\begin{array}{c}\text { Fault } \\
\text { Condition } \\
\text { Amplitudes }\end{array}$ & $\begin{array}{c}\text { Variation } \\
(\mathrm{dB})\end{array}$ \\
\hline 1400 & $\begin{array}{c}-87.49,- \\
66.82,-60.43\end{array}$ & $\begin{array}{c}-65.31,- \\
44.48,-38.28\end{array}$ & 22 \\
\hline 1370 & $\begin{array}{c}-73.7,-66.71, \\
-56.97\end{array}$ & $\begin{array}{c}-45.62,- \\
38.55,-28.60\end{array}$ & 28 \\
\hline
\end{tabular}

\section{Conclusions}

A non-intrusive approach has been developed in this paper to detect the gear damages in the electromechanical power transmission system. The test setup has been developed to simulate the condition monitoring system for gear fault diagnostics. The frequency vs amplitude spectrum has been plotted for the instantaneous power of the motor. The amplitude difference has been observed at the gear harmonics which give indication of the gear faults presence. The developed system has successfully diagnosed the fault at the motor operating speeds $1400 \mathrm{rpm}$ and $1370 \mathrm{rpm}$. It has been concluded that the developed system is capable to diagnose the gear faults and the developed system should be further tested for the diagnostics of bearing faults, shaft misalignments, eccentricity and pump impeller faults. 


\section{Acknowledgement}

The authors acknowledge the support from the Najran University Saudi Arabia for providing research facilities.

\section{References}

[1] Nooli P. K., "A versatile and computationally efficient condition indicator for AH-64 rotorcraft gearboxes," Degree of Master of Science University of South Carolina, 2011.

[2] Muhammad Irfan, Nordin Saad, and Alwadie A, "An Automated Spectral Extraction Algorithm for the Fault Diagnosis of Gears," Journal of Failure Analysis and Prevention, Vol. 19, No.1, pp. 98105, February 2019

[3] Saad, N.; Irfan, M.; Ibrahim, R. Condition Monitoring and Faults Diagnosis of Induction Motors: Electrical Signature Analysis; CRC Press \& Routledge-Taylor \& Francis Group: Boca Raton, FL, USA, 2018; ISBN 9780815389958.

[4] Al-Arbi, Salem, "Condition monitoring of gear systems using vibration analysis," Doctoral thesis, University of Huddersfield, 2012.

[5] Muhammad Irfan, Nordin Saad, Rosdiazli Ibrahim and Vijanth S Asirvadam, "Analysis of Bearing Outer Race Defects in Induction Motors," The 5th IEEE International Conference on Intelligent and Advanced Systems (ICIAS), Malaysia, June 2014.

[6] Muhammad Irfan, Nordin Saad, Rosdiazli Ibrahim, Vijanth S Asirvadam and Muawia Magzoub, "An Online Fault Diagnosis System for Induction Motors via Instantaneous Power Analysis," Tribology Transactions, Vol. 60, No. 4, pp. 592-604, July 2017.

[7] Kia, S.H., Henao, H., Capolino, G.A.: Gear tooth surface damage fault detection using induction machine stator current space vector analysis. IEEE Transactions on Industrial Electronics, vol. 62, issue 3, pp. 1866-2001, 2015.

[8] Muhammad Irfan, Nordin Saad, Rosdiazli Ibrahim and Vijanth S Asirvadam, "A Non Invasive Fault Diagnosis System for Induction Motors in Noisy Environment," IEEE International Conference on Power and Energy (PECon), Malaysia, December 2014.

[9] Muhammad Irfan, Nordin Saad, Rosdiazli Ibrahim, Vijanth S Asirvadam, Alwadie A, Nursynrizal and M. Aman "A hardware and software integration approach for development of a noninvasive condition monitoring systems for motor-coupled gears faults diagnosis," Modeling, Design and Simulation of Systems, vol. 751, pp. 642-655, August 2017.

[10] Chacon, J.L.F.; Andicoberry, E.A.; Kappatos, V.; Asfis, G.; Gan, T.H.; Balachandran, W. Shaft angular misalignment detection using acoustic emission. Appl. Acoust., 85, 12-22. 2014.
[11] Hamel, M.; Addali, A.; Mba, D. Investigation of the influence of oil film thickness on helical gear defect detection using Acoustic Emission. Appl. Acoust., 79, 42-46, 2014.

[12] Abad, M.R.A.A.; Ahmadi, H.; Moosavian, A.; Khazaee, M. Kohan, M.R.; Mohammadi, M. Discrete wavelet transform and artificial neural network for gearbox fault detection based on acoustic signals. J. Vibroeng, 15, 459-463, 2013.

[13] Li, C.; Sanchez, V.; Zurita, G.; Lozada, M.C.; Cabrera, D. Rolling element bearing defect detection using the generalized synchrosqueezing transform guided by time-frequency ridge enhancement. ISA Trans., 60, 2016.

[14] Li, C.; Liang, M. Time-frequency signal analysis for gearbox fault diagnosis using a generalized synchorosqueezing transform. Mech. Syst. Signal Process., 26, 205-217, 2012.

[15] Chen, F.; Tang, B.; Chen, R. A novel fault diagnosis model for gearbox based on wavelet support vector machine with immune genetic algorithm. Measurement, 46, 220-232, 2013.

[16] Emmanuel Resendiz-Ochoa, Juan J. Saucedo-Dorantes , Juan P. Benitez-Rangel, Roque A. Osornio-Rios and Luis A. MoralesHernandez, "Novel Methodology for Condition Monitoring of Gear Wear Using Supervised Learning and Infrared Thermography," Applied Sciences, January 2020.

[17] Salameh, J.P.; Cauet, S.; Etien, E.; Sakout, A.; Rambault, L. Gearbox condition monitoring in wind turbines: A review. Mech. Syst. Signal Process., 111, 251-264, 2018.

[18] Ardakani, H.D.; Liu, Z.; Lee, J.; Bravo-Imaz, I.; Arnaiz, A. Motor Current Signature Analysis for Gearbox Fault Diagnosis in Transient Speed Regimes. In Proceedings of the 2015 IEEE Conference on Prognostics and Health Management (PHM), Austin, TX, USA, 22-25 June 2015. 